\title{
Abstract \\ Awareness on non communicable diseases among advanced level students in rural health settings, Sri Lanka
}

Hirimuthugoda $\mathrm{LK}^{1 *}$, Wadikawage $\mathrm{SR}^{2}$, Wijethunga $\mathrm{CW}^{3}$, Gamage $\mathrm{APJ}^{4}$, Priyantha $\mathrm{S}^{5}$, Priyantha $\mathrm{M}^{6}$

${ }^{1}$ National Institute of Health Sciences, Kalutara

${ }^{2}$ General hospital, Matara

${ }^{3}$ Medical officer of Health, Ambalantota

${ }^{4}$ Medical officer of Health, Beliatta

${ }^{5}$ District hospital, Beliatta

${ }^{6}$ Medical officer of Health, Okawela

\begin{abstract}
Background

High prevalence of poor knowledge, awareness, and practice on chronic non communicable diseases (NCD) has increased premature death, costly complications, and financial burden. School going populations' awareness and practices are crucial components in reducing the burden of diseases and its complications in future. The main aim of the study was to assess school going young populations' knowledge about NCD, its causes and complications and the methods which they used to get to know about NCD.

\section{Methods}

A school based cross-sectional study was conducted in rural area of Sri Lanka selecting a total of 700 school children using self-administered questionnaire. Data were analyzed using SPSS software, version 17. Chi-square and $\mathrm{Z}$ test were used for test of significance and considered statistically significant at $\mathrm{P}<0.05$.

\section{Results}

Of 700 participants, $30.6 \%$ of boys were aware of NCD while only $15.6 \%$ of the girls were aware. There were $10.1 \%$ of students who knew about the NCD and among them, 5.4\% were aware on causes for NCD. Most of the students obtained the knowledge on NCD through NCD patients who were living with them. Significantly less subjects $(61.3 \%, 19 / 31)$ of girls than boys $(85.1 \%, 57 / 67)$ could name at least one complication of NCD $(\mathrm{P}<0.01$, odds ratio $[\mathrm{OR}]=3.6,95 \%$ confidence interval $[\mathrm{CI}]=1.3-5.6)$. Significant number of students acquired knowledge about NCD through patients at home than other modes of media $(\mathrm{P}=0.02, \mathrm{OR}=6.2,95 \% \mathrm{CI}=1.1-14.2)$.

\section{Conclusion}

Young population needs to be made aware of NCD, its causes and long-term complications. At the same time, efforts should be made to sensitize them through media and to make them realize the importance of knowing.
\end{abstract}

Key words: Awareness; Advanced level student; Media; Non communicable diseases

Copyright: (C) 2015 Hirimuthugoda LK et al. This is an open access article distributed under the Creative Commons Attribution License, which permits unrestricted use, distribution, and reproduction in any medium, provided the original work is properly cited.

* Correspondence : krishan824@yahoo.com

Cite this abstract as: Hirimuthugoda LK, Wadikawage SR, Wijethunga CW, Gamage APJ, Priyantha S, Priyantha M. Awareness on non communicable diseases among Advanced Level students in rural health settings, Sri Lanka . Anuradhapura Medical Journal 2015;9 (2Supp):S21. DOI: http://dx.doi.org/10.4038/amj.v9i2Supp.7570 
